\title{
Ursodeoxycholic acid therapy in chronic active hepatitis
}

\author{
Malcolm C. Bateson
}

General Hospital, Bishop Auckland, County Durham, DL14 6AD, UK.

\begin{abstract}
Summary: A 41 year old woman developed chronic active hepatitis with prominent cholestasis. She was treated with prednisolone over 3 years with symptomatic benefit and improvement in serum biochemistry. However, various steroid-related side effects were encountered and steatorrhoea eventually occurred with very troublesome nocturnal diarrhoea. Therapy with ursodeoxycholic acid $750 \mathrm{mg}$ daily was started. Serum alanine aminotransferase and gamma-glutamyl transferase normalized for the first time since her illness began. Steatorrhoea was abolished. There was good control of symptoms as prednisolone therapy was gradually reduced. However, when prednisolone was completely withdrawn there was a prompt biochemical deterioration. Addition of low-dose azathioprine has maintained normal blood tests over 24 months without return of the original symptoms. There are no side effects of ursodeoxycholic acid in subjects without gallstones and this agent may be effective treatment for cholestatic liver disease.
\end{abstract}

\section{Introduction}

Management of auto-immune chronic active hepatitis is based on the appropriate use of corticosteroids, ${ }^{1-3}$ perhaps with adjuvant azathioprine therapy ${ }^{1,3}$ but treatment is often limited by side effects and not all patients show a complete response. A case is described in which ursodeoxycholic acid (UDCA) produced symptom relief and biochemical improvement where steroids alone had not been completely successful.

\section{Case report}

The patient was a Caucasian female born in 1941 . In February 1983 she developed an acute illness with lethargy, abdominal pain, vomiting, jaundice and dark urine with pale stools. She gave an additional history of pruritis without skin rash over the previous year. On examination she was jaundiced with right upper quadrant abdominal tenderness but no stigmata of chronic liver failure. Investigations showed a serum bilirubin of $55 \mu \mathrm{mol} / \mathrm{l}$, alkaline phosphatase $160 \mathrm{IU} / \mathrm{l}$, alanine aminotransferase (ALT) $250 \mathrm{IU} / 1$, gammaglutamyl transferase (GT) $320 \mathrm{IU} / \mathrm{l}$, albumin $31 \mathrm{~g} / \mathrm{l}$, immunoglobulins IgG $34 \mathrm{~g} / \mathrm{l}$, IgA $5.9 \mathrm{~g} / \mathrm{l}$ and $\mathrm{IgM}$ $1.1 \mathrm{~g} / \mathrm{l}$. Smooth muscle antibody was positive to a titre of $1 / 40$. Mitochondrial antibody and nuclear

Correspondence: M.C. Bateson M.D., F.R.C.P., F.R.C.P. (Edin)

Accepted: 20 April 1990 antibody tests were negative. She was hepatitis B surface antigen negative, and also negative for anti-hepatitis A virus IgM fraction, Epstein-Barr virus and cytomegalovirus antibodies. Serum ferritin, caeruloplasmin and $\alpha$-antitrypsin were normal, as was $25-\mathrm{OH}$ cholecalciferol, though $25-\mathrm{OH}$ ergocalciferol was below the level of detection. Haemoglobin was $12.6 \mathrm{~g} / \mathrm{dl}$, but prothrombin ratio was 1.5 and the platelet count was $75 \times 10^{9} / 1$, so a percutaneous liver biopsy was deferred.

She had persistent malaise and abdominal discomfort with fluctuant jaundice over the next few months, and in September 1983 a percutaneous liver biopsy was performed which showed the presence of chronic active hepatitis with cirrhosis. Although her serum bilirubin had fallen to $25 \mu \mathrm{mol} / 1$ the other liver function tests remained markedly abnormal. She was started on prednisolone $15 \mathrm{mg}$ daily with good control of symptoms over the succeeding 18 months. There was a prompt sustained biochemical improvement, which became normal apart from an ALT of $55-65 \mathrm{IU} / 1$ and a GT of $160-170 \mathrm{IU} / 1$. Subsequent reduction of the dose of prednisolone to $10 \mathrm{mg}$ per day in 1985 was accompanied by a relapse of symptoms with malaise and abdominal discomfort, but no deterioration of liver function tests. She was, therefore, maintained on $12.5 \mathrm{mg}$ daily of prednisolone, but this was associated with many problems. She developed persistent extensive tinea versicolor, which was eradicated by a course of ketoconazole. She also had recurrent vaginal candidiasis, managed by courses of clotrimazole. There was weight gain from 58 to $69 \mathrm{~kg}$, and she developed such prominent ankle oedema that she required maintenance diuretic therapy with 
frusemide and amiloride.

In 1987 she had gradually worsening diarrhoea with yellow offensive stools, at least 4 times daily and often up to 8 times daily. There was very troublesome nocturnal diarrhoea. The plasma glucose was normal, but the triolein breath test was not, with an excretion of carbon ${ }^{14} \mathrm{CO}_{2}$ of $0.29 \%$ per dose per millimol $\mathrm{CO}_{2}$ per kilogram body weight (normal greater than $0.4 \%$ ).

Because it was felt that she was suffering from steatorrhoea resulting from deficient bile acids in the intestinal lumen secondary to cholestatic liver disease, she was started on ursodeoxycholic acid $750 \mathrm{mg}$ daily in April 1987. Her diarrhoea was completely abolished and she thereafter suffered from intermittent mild constipation with bowel actions daily or on alternative days. The triolein breath test normalized at $0.43 \%$ when repeated after 4 months on UDCA treatment. The serum biochemistry became completely normal for the first time and remained so over 6 months, during which time the dose of prednisolone was gradually reduced and eventually withdrawn. In addition, the immunoglobulins also became normal for the first time. Symptoms of the disease were completely controlled and steroid side effects generally disappeared, but following a trivial fall at a time when she was still receiving prednisolone $5 \mathrm{mg}$ daily she had multiple femoral fractures, attributed partly to steroid-induced osteoporosis.

By November 1987 steroid therapy had been completely withdrawn, but there was a prompt biochemical relapse. ALT rose from $42 \mathrm{IU} / 1$ to $85 \mathrm{IU} / 1$ after 2 months and $555 \mathrm{IU} / 1$ after 4 months, when her IgG also rose to $18.8 \mathrm{~g} / \mathrm{l}$. She was started on azathioprine $150 \mathrm{mg}$ daily, which was reduced over 10 months to $25 \mathrm{mg}$ daily because of neutropenia on higher doses. On this regime, together with continued UDCA $750 \mathrm{mg}$ daily, she has had normal serum biochemistry for 24 months and has had no relapse of symptoms.

\section{References}

1. Stellon, A.J., Keating, J.J., Johnson, P.J., McFarlane, I.G. \& Williams, R. Maintenance of remission in autoimmune chronic active hepatitis with azathioprine after corticosteroid withdrawal. Hepatology 1988, 8: 781-784.

2. Czaja, A.J., Beaver, S.J. \& Shiels, M.T. Sustained remission after corticosteroid therapy of severe hepatitis B surface antigen negative chronic active hepatitis. Gastroenterology 1987, 92: 215-219.

3. Schaffner, F. Autoimmune chronic active hepatitis: three decades of progress. Prog Liver Dis, 1986, VIII: 485-503.

4. Somayaji, B.N., Paton, A., Price, J.H., Harris, A.W. \& Flewett, T.H. Norethisterone jaundice in two sisters. $\mathrm{Br}$ Med $J$ 1968, ii: $281-282$.

\section{Discussion}

The aetiology of this patient's chronic active hepatitis was auto-immune disease. Though treatment with norethisterone was given for up to 4 months before this illness began, and this agent is known to cause cholestatic liver disease, ${ }^{4}$ this occurs early after commencement of such treatment, is self-limiting, and has different histological appearances.

Standard management of auto-immune chronic active hepatitis is based on the use of prednisolone together with specific treatment of other problems as they arise. Replacement therapy for fat-soluble vitamin deficiencies is useful in therapy, but probably not as prophylaxis. Management of pruritus has been difficult but cholestyramine, terfenadine and phototherapy have all been employed. Azathioprine may be useful as an adjunct to reduce the requirement for steroid treatment. Liver transplant may be indicated for severe disease and offers the only possibility of a cure. Although other agents such as cyclosporin have been proposed, ${ }^{5}$ potential toxicity limits usefulness.

In cholestasis there is an accumulation of native bile acids in the serum which may explain pruritis; there is intra-hepatic blue acid recycling which mayo perpetuate and exacerbate liver cell injury; ando there is defective secretion of bile acid into the intestine which may cause steatorrhoea ${ }^{6,7}$ Dilution of the apparently more toxic native bile acids with UDCA therapy may be expected to improve al these factors. ${ }^{8}$ UDCA has been used in management of primary biliary cirrhosis, ${ }^{9-11}$ sclerosing cholangitis $^{12}$ and chronic active hepatitis, ${ }^{10,13}$ though some of the initial experience was merely an anecdotal, incidental to the management of gallstone disease. The case described suggests that UDCA is of general benefit in cholestatic liver disease, though occasional adverse effects are a possibility. ${ }^{14}$

5. Hyams, J.S., Ballow, M. \& Leichtner, A.M. Cyclosporine treatment of autoimmune chronic active hepatitis. Gastroenterology 1987, 93: 890-893.

6. Palmer, R.H. Bile acids, liver injury and liver disease. Arch Int Med 1972, 130: 606-617.

7. Akashi, Y., Miyazaki, H., Yanagisawa, J. \& Nakayama, F. Bile acid metabolism in cirrhotic liver tissue - altered synthesis and impaired hepatic secretion. Clin Chim Acta 1987, 168: 199-206.

8. Miyazaki, K., Nakayama, F. \& Koga, A. Effects of chenodeoxycholic and ursodeoxycholic acids on isolated adult human hepatocytes. Dig Dis Sci 1984, 12: 1123-1130. 
9. Poupon, R., Poupon, R.E., Calmus, Y., Chretien, Y., Ballet, F. \& Darnis, F. Is ursodeoxycholic acid an effective treatment for primary biliary cirrhosis? Lancet 1987, i: 834-836.

10. Podda, M., Ghezzi, C., Battezzati, P.M. et al. Ursodeoxycholic acid for chronic liver diseases. $J$ Clin Gastroenterol 1988, 10: S25-S31.

11. Bateson, M.C., Ross, P.E. \& Diffey, B.L. Ursodeoxycholic acid in primary biliary cirrhosis. Lancet 1989 , i: 898-899.

12. Leuschner, U. \& Kurtz, W. Treatment of primary biliary cirrhosis and cholestatic disorders with UDCA. Lancet 1987, ii: 508 .
13. Leuschner, U., Leuschner, M., Sieratzki, J., Kurtz, W. \& Hubner, K. Gallstone dissolution with ursodeoxycholic acid in patients with chronic active hepatitis and two years follow-up. A pilot study. Dig Dis Sci 1985, 7: 642-649.

14. Vogel, W., Kathrein, H., Judmaier, G. \& Braunsteiner, R.H Deterioration of primary biliary cirrhosis during treatment with ursodeoxycholic acid. Lancet 1988, i: 1163. 